\title{
Force awakens: a new hope for athletic shoulder strength testing
}

\author{
Ben Ashworth, ${ }^{\oplus 1}$ Daniel Dylan Cohen ${ }^{2}$
}

\begin{abstract}
'Lucas [real identity hidden] came through the training session yesterday with no issues. It is now ten weeks since his posterior shoulder repair (non-dominant) and he is pushing to play this Saturday, but his goalkeeper coach says he still looks apprehensive at full stretch and when he has to react or land from a dive. Clinically, his shoulder instability tests are all normal and he has full range of motion. Upper body strength in the gym and all grip strength and hand-held dynamometer scores are back to preinjury levels.

However, there remain meaningful differences in peak landing force when he performs a plyometric push up (17\% offload asymmetry), and the 'ASH test' shows a $23 \%$ lower rate of force development in a T-position on the affected left shoulder $(445 \mathrm{~N} / \mathrm{s}$ vs $580 \mathrm{~N} / \mathrm{s}$, table 1). This suggests that when he has to stabilize quickly, his shoulder is not ready yet. In my opinion he is a risk for the weekend.'
\end{abstract}

At present, there are few objective markers to support return to performance decisions in athletes following shoulder operation or injury. ${ }^{12}$ The athlete with a shoulder injury requires a testing protocol that is appropriately challenging, yet sensitive enough to inform decisions along the full return to play continuum (figure 1). Novel tests performed on a force platform such as the ASH test and plyometric push up (PPU) should only be added if they add information that current field based testing tools, such as hand-held dynamometry (HHD) do not provide. ${ }^{3}$ Appropriate clinical tests need validity, reliability and sensitivity (evidence base), while recognising the need to use innovative studies of elite populations where an identified knowledge gap exists (evidence lead). ${ }^{4}$

The force platform tests require a higher level of shoulder function that tests the ability to generate force (HHD and grip strength), and the rateand strategy of force development, corresponding to key components of performance and injury prevention. ${ }^{5}$ The 'ASH test' was developed specifically to replicate long-lever stress

${ }^{1}$ Sports Medicine and Performance team, Arsenal Football Club, St Albans, UK

${ }^{2}$ Faculty of Life Sciences, Universidad de Santander (UDES), Bucaramanga, Colombia

Correspondence to Ben Ashworth, Arsenal Football Club, London AL2 1DR, UK; bennyashworth@gmail.com and the ability to transfer force across the shoulder girdle during the arm tackle in rugby (figure 2). Preliminary data from elite-level rugby players suggest excellent reliability. ${ }^{3}$ The test exposes players to a maximal isometric contraction where they are required to produce force as fast and hard as possible, comparable to established tests of neuromuscular function in the lower limb. ${ }^{6}$ The test cannot tell you what is wrong, but it can suggest that something is wrong.

The capacity or 'willingness' to accept high load at high velocity is challenged in the 'landing' phase of PPU. In the opening clinical case force production in the isometric test has returned to normal, but the rate of force development remains lower than we believe it should be (compared with the other side). A conventional output variable such as peak force provides a blunt tool in comparison to more sensitive force production (rate) metrics that have implications around player capacity for explosive performance and joint protection..$^{7}$ These lag behind peak force recovery during rehabilitation following lower body injury.
Bilateral performance in the push-off phase of the PPU relates to tackling ability ${ }^{8}$ but assessing force symmetry in the landing phase could provide an indicator of the shoulder's load acceptance capacity.

There is evidence that athletes with previous knee injury show patterns of involved side offloading on landing from jumps that suggest a reduction in deceleration and load acceptance capacity. ${ }^{9}$ Decisions concerning player readiness to return to sport following injury can be supported by adopting rate and acceptance metrics into current approaches. When balancing the player's subjective confidence against the goalkeeping coach's concern in the player's performance level, the objective results (ASH test and PPU) indicate that the goalkeeper will likely be unable to react with enough force to stabilise the shoulder in positions that matter, and to tolerate the demands of elite-level competition.

The introduction of innovative tests should follow a structured process to establish trust in the data collected and ensure that these tests stand up to the necessary scientific rigour to be considered valid, repeatable and reliable. ${ }^{10}$ There is still a long journey ahead to better understand monitoring tools that impact on decisions relating to athletic shoulder health and performance. Reliable methods of identifying deficits in rate of force production in instances where peak force has returned to

\begin{tabular}{|c|c|c|c|c|c|c|c|c|c|c|}
\hline \multirow[b]{3}{*}{ Post op } & \multicolumn{4}{|c|}{ Athletic shoulder test (T-position)* } & \multicolumn{2}{|c|}{ HHDt } & \multicolumn{2}{|c|}{ Grip strength } & \multicolumn{2}{|c|}{ Plyometric push-up $¥$} \\
\hline & \multicolumn{2}{|c|}{$\begin{array}{l}\text { Net peak force } \\
\text { (NPF) (N) }\end{array}$} & \multicolumn{2}{|c|}{$\begin{array}{l}\text { RFD 0-100 mst } \\
+(\mathrm{N} / \mathrm{s})\end{array}$} & \multicolumn{2}{|c|}{ Prone ER $(\mathrm{kg})$} & \multicolumn{2}{|c|}{ Neutral grip (kg) } & \multicolumn{2}{|c|}{ Peak landing } \\
\hline & Left & Right & Left & Right & Left & Right & Left & Right & (N) & Asymmetry \\
\hline Week 6 & 88.4 & 115.0 & 367 & 591 & 16.5 & 23.0 & 56.1 & 56.4 & $\mathrm{~N} / \mathrm{a} \|$ & \\
\hline Week 10 & 121.2 & 118.9 & 445 & 580 & 21.0 & 21.3 & 57.4 & 63.5 & 1939 & $17 \% R^{* *}$ \\
\hline
\end{tabular}

${ }^{*}$ Single force platform unilateral test-player lying prone with straight arm abducted to $90^{\circ}$ (figure 2).

tHand-held dynamometry (make test) - Prone External Rotation (ER) at 90 degrees Abduction.

‡Dual force platform bilateral test.

$\S$ Net peak force=total peak force-force at start of contraction.

१N/a; not applicable_-plyometric push-ups not performed until week 8 postop.

${ }^{*} \mathrm{R}=$ increased peak landing force on the right upper limb $(17 \%$ higher than left in this example (bold values indicate true deficits).

t+RFD 0-100 ms; average rate of force development over the first $100 \mathrm{~ms}$ after the start of contraction - $23 \%$ lower rate of force development in a T-position on the affected left shoulder (bold values).

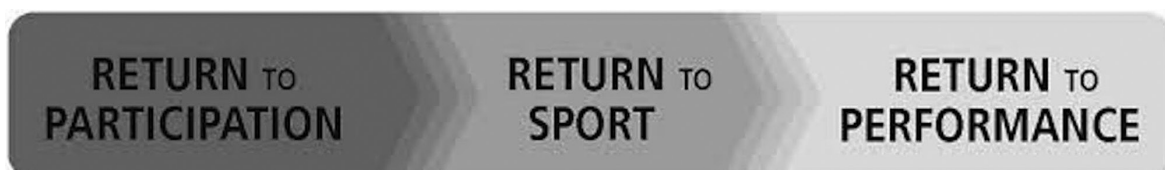

Figure 1 The three elements of the return to sport continuum. ${ }^{1}$ 

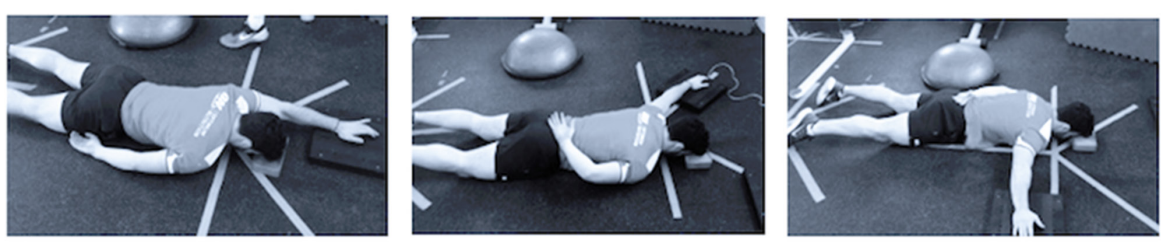

A
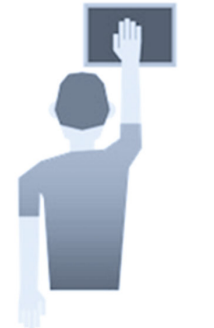

B
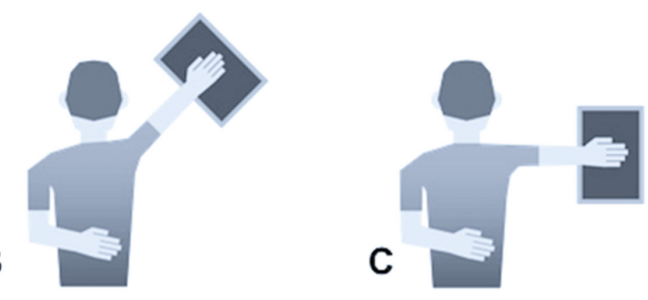

Figure 2 The ASH test. (A) I position, (B) Y position, (C) T position. ${ }^{1}$

preinjury levels will challenge existing test protocols used in rugby, baseball, swimming and other sports where the demands on the shoulder are highest. The information provided by force platforms bridges a gap in upper limb monitoring and return to play assessment that can help clinicians and sports medicine teams to reach better answers.

Acknowledgements The authors would like to thank Patrick Hogben, Laura Tulloch (Saracens RFC) and Navraj Singh (Arsenal FC) for their contributions to the conception of this work and assistance with revisions, data analysis and final approval.

Contributors BA and DDC contributed equally to this paper. Both authors gave substantial contributions, to the conception of the work, analysis and interpretation of data, drafting the work or revising it critically for important intellectual content, final approval of the version published and agreement to be accountable for all aspects of the work in ensuring that questions related to the accuracy or integrity of any part of the work are appropriately investigated and resolved.
Funding The authors have not declared a specific grant for this research from any funding agency in the public, commercial or not-for-profit sectors.

Competing interests $\mathrm{DDC}$ is a shareholder in NMP technologies. who have commercialised the "ForceDecks" proprietary software used in data acquisition and analysis. Since the original submission of this editorial, BA now performs consultancy for Vald Performance.

Patient consent Not required.

Provenance and peer review Not commissioned; externally peer reviewed.

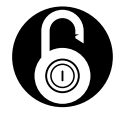

\section{OPEN ACCESS}

Open access This is an open access article distributed in accordance with the Creative Commons Attribution Non Commercial (CC BY-NC 4.0) license, which permits others to distribute, remix, adapt, build upon this work non-commercially, and license their derivative works on different terms, provided the original work is properly cited, appropriate credit is given, any changes made indicated, and the use is non-commercial. See: http:// creativecommons.org/licenses/by-nc/4.0/.

(C) Author(s) (or their employer(s)) 2019. Re-use permitted under CC BY-NC. No commercial re-use. See rights and permissions. Published by BMJ.

D) Check for updates

To cite Ashworth B, Cohen DD. Br J Sports Med 2019;53:524.

Accepted 22 September 2018

Published Online First 9 November 2018

Br J Sports Med 2019;53:524.

doi:10.1136/bjsports-2018-099457

\section{REFERENCES}

1 Ardern CL, Glasgow P, Schneiders A, et al. 2016 Consensus statement on return to sport from the First World Congress in Sports Physical Therapy, Bern. Br J Sports Med 2016;50:853-64.

2 Cools AM, Johansson FR, Borms D, et al. Prevention of shoulder injuries in overhead athletes: a science-based approach. Braz J Phys Ther 2015;19:331-9.

3 Ashworth B, Hogben P, Singh N, et al. The Athletic Shoulder (ASH) test: reliability of a novel upper body isometric strength test in elite rugby players. BMJ Open Sport Exerc Med 2018;4:e000365.

4 Coutts AJ. Working fast and working slow: the benefits of embedding research in high performance sport. Int $\mathrm{J}$ Sports Physiol Perform 2016;11:1-2.

5 Maffiuletti NA, Aagaard P, Blazevich AJ, et al. Rate of force development: physiological and methodological considerations. Eur J Appl Physiol 2016;116:1091-116.

6 McCall A, Nedelec M, Carling C, et al. Reliability and sensitivity of a simple isometric posterior lower limb muscle test in professional football players. J Sports Sci 2015;33:1298-304.

7 Knezevic OM, Mirkov DM, Kadija M, et al. Asymmetries in explosive strength following anterior cruciate ligament reconstruction. Knee 2014;21:1039-45.

8 Speranza MJA, Gabbett TJ, Greene DA, et al. An alternative test of tackling ability in rugby league players. Int J Sports Physiol Perform 2018;13:347-52.

9 Paterno MV, Ford KR, Myer GD, et al. Limb asymmetries in landing and jumping 2 years following anterior cruciate ligament reconstruction. Clin I Sport Med 2007;17:258-62.

10 Impellizzeri FM, Marcora SM. Test validation in sport physiology: lessons learned from clinimetrics. Int J Sports Physiol Perform 2009;4:269-77. 